\title{
Preparation of CL-20 Explosive Nanoparticles and Their Thermal Decomposition Property
}

\author{
Dunju Wang, 1,2 Bing Gao, ${ }^{3}$ Guangcheng Yang, ${ }^{3}$ Fude Nie, ${ }^{3}$ and Hui Huang ${ }^{1,3}$ \\ ${ }^{1}$ School of Chemical Engineering, Nanjing University of Science and Technology, Nanjing 210094, China \\ ${ }^{2}$ Co-Innovation Center for Energetic Materials, Southwest University of Science and Technology, Mianyang 621010, China \\ ${ }^{3}$ Institute of Chemical Materials, China Academy of Engineering Physics, Mianyang 621900, China \\ Correspondence should be addressed to Hui Huang; hhui0816@126.com
}

Received 18 November 2015; Revised 4 February 2016; Accepted 14 February 2016

Academic Editor: Gaurav Mago

Copyright (C) 2016 Dunju Wang et al. This is an open access article distributed under the Creative Commons Attribution License, which permits unrestricted use, distribution, and reproduction in any medium, provided the original work is properly cited.

\begin{abstract}
Herein, we develop a novel method for preparing nanohexanitrohexaazaisowurtzitane (nano-CL-20) via ultrasonic spray-assisted electrostatic adsorption (USEA) technology. Various experimental conditions which influence safety factors and the crystallization process were studied. Meanwhile, the prepared nano-CL-20 particles were characterized by field emission scanning electron microscopy (FE-SEM), X-ray diffraction (XRD), and Fourier transform infrared (FT-IR) spectroscopy. The results show that the obtained nano-CL-20 showed a wide size distribution in the range from 150 to $600 \mathrm{~nm}$ with an average of $270 \mathrm{~nm}$. Moreover, their thermal properties were also investigated by differential scanning calorimetry (DSC) and thermogravimetry (TG). For nano-CL20 , the exothermal peak is $232.9^{\circ} \mathrm{C}$ increased by $12^{\circ} \mathrm{C}$ compared with conventionally manufactured (CM) CL-20, and they exhibit fast energy release efficiency as well as more energy release. The simple and continuous approach presented here is expected to be an attractive potential for fabricating other organic nanoparticles.
\end{abstract}

\section{Introduction}

2, 4, 6, 8, 10, 12-Hexanitro-2,4,6,8,10,12-hexaazaisowurtzitane (CL-20) which was firstly synthesized in 1987 by Nielsen et al. [1] is one of the most recently developed energetic materials (Figure 1) [2-4]. It has highest crystal density and highest detonation velocity among high energetic materials, which has a promising prospect of application. However, due to the relatively high mechanical sensitivity, the common conventionally manufactured (CM) CL-20 does not have many practical applications. Nanoscale energetic materials have significant advantages such as good stability, excellent security, fast energy release rate, and high energy density $[5,6]$. It was reported that CL-20 becomes more insensitive and its decomposition rate increases as the particle size is reduced. The development of energetic materials with improved performance, yet reduced sensitivity, is a major objective in the advancement of high density energetic materials [7]. According to Elbeih and Zohari [8,9], the physical characteristics of crystals such as regular smooth particles and having a small size show significant associations with impact sensitivity.
In the recent years, various methods have been used to prepare nanoenergetic materials, such as grinding and milling [10], solvent-nonsolvent recrystallization [11], microemulsion [5], and rapid expansion of supercritical solution [12]. These were developed to obtain ultrafine particles. Milling and grinding are general methods for reducing particle size. However, these methods are not recommended for the preparation of explosives nanoparticles due to damage of surface crystal. Nanoscale energetic materials were also prepared by solvent-nonsolvent recrystallization. However, the filtration of crystal suspension is a very time-consuming process for nanometer sized particles. Although nanoparticles sizes are obtained from microemulsion, there is still some residual polymer on the surface of nanoparticles which is difficult to be eliminated completely. Obviously, supercritical fluid is an uneconomical method because of the requirement for ultrahigh pressure and exorbitant equipment.

Atomization techniques are widely utilized to manufacture nanosized particles because ultrasound can provide the phase isolation of one microdroplet reactor from another. In recent years, many different types of inorganic nanoparticles 


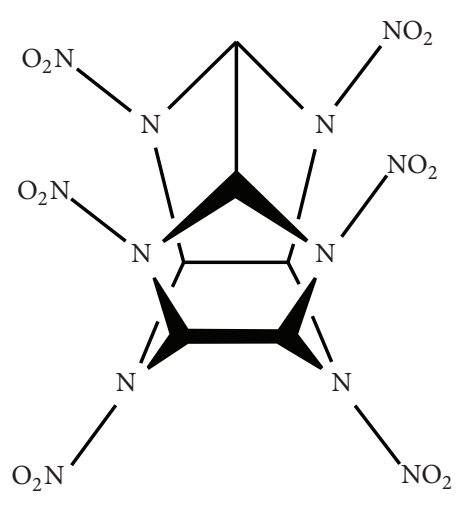

(a)

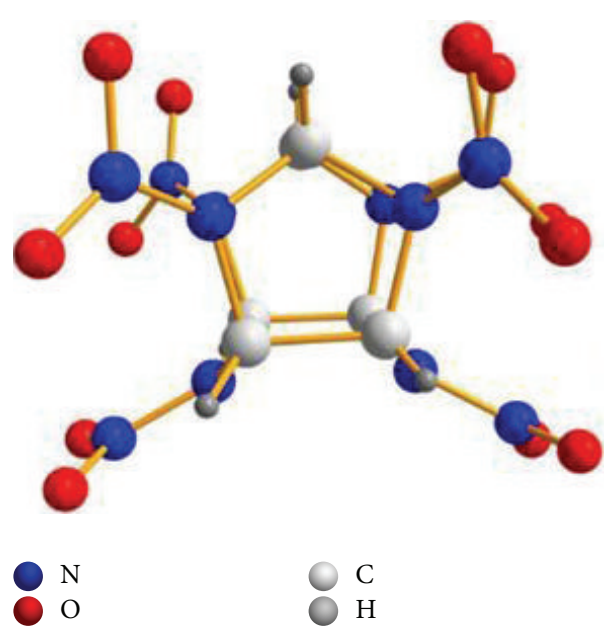

(b)

Figure 1: Planar structure of CL-20 (a) and crystal structure of CL-20 (b).

$[13,14]$ have been prepared using ultrasonic spraying, in which the apparatus is simple and continuous, and can be sized easily for mass production. In the energetic materials field [15-17], ultrasonic spray method is rarely used to manufacture nanosized explosives. Here, the objective of this study was to develop a facile and continuous method for preparing nanoscale CL-20 (nano-CL-20) explosive. Nano-CL-20 was successfully synthesized for the first time using ultrasonic spray-assisted electrostatic adsorption (USEA) method. Compared with conventional drowning-out crystallization for the preparation of nanoscale CL-20, the USEA method did not require antisolvents and can continuously prepare nanoscale CL-20. Furthermore, it is also a very effective alternative for industrial production by this electrostatic assist, making this approach particularly useful to produce other small-molecule organic nanomaterials.

\section{Methods}

2.1. Materials. CL-20 explosive (purity $=99.6 \%$, particle size 20-50 $\mu \mathrm{m}$ ) was obtained from our own laboratory. Acetone $\left(\mathrm{CH}_{3} \mathrm{COCH}_{3}, \mathrm{AR}\right.$ grade $)$ was obtained from Chengdu United Chemical Industry (Chengdu, China). High purity nitrogen $\left(\mathrm{N}_{2}, 99.999 \%\right)$ was bought from Changjun GAS Co., Ltd. (Mianyang, China). The ultrasonic nebulizer (402-B) with a series of ultrasonic frequency was supplied by YUYUE Medical Co., Ltd. (Jiangsu, China), and the Work Voltage is $220 \mathrm{~V}$; the ultrasonic transducer frequency is $1.7 \pm 0.17 \mathrm{MHz}$.

2.2. Preparation of Microsized CL-20. Micro-CL-20 particles were prepared by ball milling method. Briefly, about $15 \mathrm{~g}$ of CM CL-20 was milled by using $\mathrm{Zro}_{2}$ ball (mean diameter $1.6 \mathrm{~mm}$ ) dispersed in water liquid medium under stirring $(150 \mathrm{rpm})$ at $0^{\circ} \mathrm{C}$ for 8 hours. After filtration, lavation, and freeze-drying, the micro-CL-20 samples were obtained.

2.3. Preparation of Nanosized CL-20. About $0.25 \mathrm{~g}$ of CM CL-20 is dissolved into $50.0 \mathrm{~mL}$ acetone (solvent) in a concentration below the saturation point at $25^{\circ} \mathrm{C}$. The ultrasonic spray-assisted electrostatic experimental installation which is designed by our own laboratory was seen in Supporting Information Figure 1[SI] (see Supplementary Material available online at http://dx.doi.org/10.1155/2016/5462097). $95 \mathrm{mg}$ nanoscale CL-20 was collected, resulting in a product yield of $38 \%$. The preparation and process in detail and a brief representation of the apparatus are seen in the Supporting Information (SI) I.

2.4. Characterization. The morphology and surface appearance of the nano-CL-20 particles were characterized by field emission scanning electron microscopy (FE-SEM, Ultra-55, Carl Zeiss, Germany) at an acceleration voltage of $10 \mathrm{kV}$ after gold sputtering coating under the vacuum degree of $10^{-6} \mathrm{~Pa}$ for 50 seconds.

The average size and particle size distribution of CL-20 were calculated by means of counting more than 300 particles from the obtained SEM images via the statistics of the smile view software.

The phase content of CL-20 was determined by X-ray diffraction (XRD, X'Pert Pro, PANalytical) analysis using $\mathrm{Cu}$ $\mathrm{K} \alpha(\lambda=1.540598 \AA)$ radiation at $50 \mathrm{kV}$ and $30 \mathrm{~mA}$ and $\mathrm{a}$ graphite diffracted-beam monochromator. The samples were packed into an amorphous silicon holder and the diffraction angle $(2 \theta)$ scanned from $5^{\circ}$ to $80^{\circ}$, and the scanning rate was $10 \cdot \mathrm{min}^{-1}$.

FT-IR spectra were recorded on a Broker-Tensor 27 spectrometer (FT-IR, Bruker, Germany). About $150 \mathrm{mg}$ of $\mathrm{KBr}$ was ground in a mortar and pestle, and $1 \mathrm{wt} \%$ of the solid sample was ground with $\mathrm{KBr}$ in the region $4000-400 \mathrm{~cm}^{-1}$.

Samples of conventionally manufactured CL-20 and prepared nano-CL-20 were analysed with a thermogravimetrydifferential scanning calorimetry (DSC/TG, PerkinElmer Diamond, USA). The conditions of DSC were as follows: sample mass: $1.05 \mathrm{mg}$; heating rate: $10 \mathrm{~K} \cdot \mathrm{min}^{-1}$; nitrogen atmosphere (flow rate: $30 \mathrm{~mL} \cdot \mathrm{min}^{-1}$ ). 


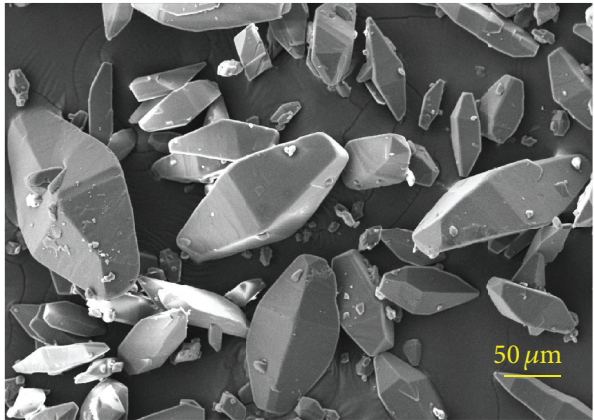

(a)

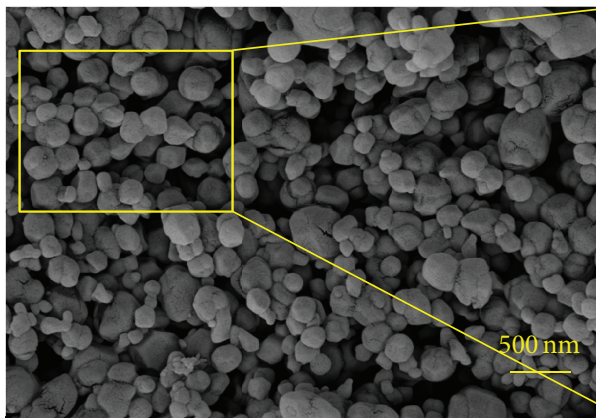

(c)

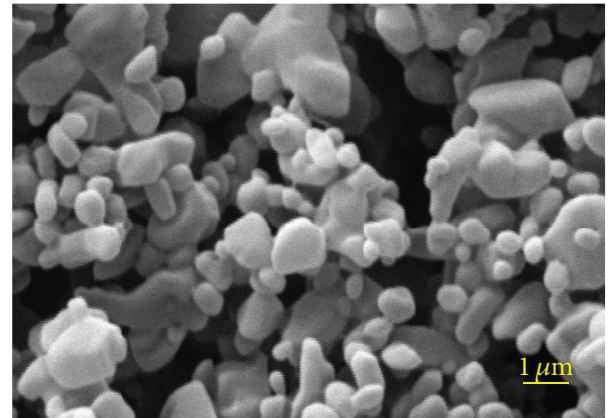

(b)

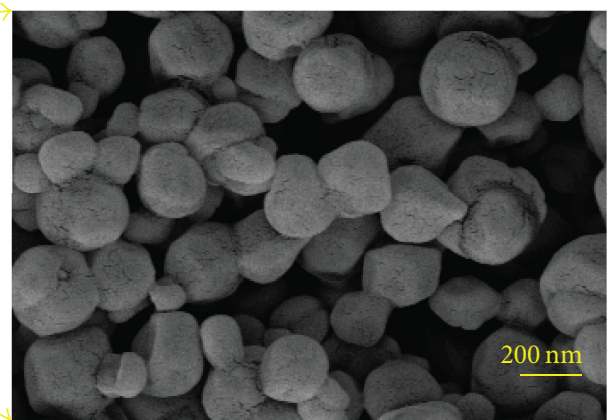

(d)

FIGURE 2: SEM images of (a) CM CL-20, (b) prepared by ball milling method at the $0^{\circ} \mathrm{C}$ conditions, (c) prepared by USEA method at the voltage of $3 \mathrm{kV}$, and (d) high magnification of images of nano-CL-20.

\section{Results and Discussion}

3.1. Morphology and Particle Size Characterization. The morphology and particle size of CL-20 were studied by FE-SEM characterizations. The FE-SEM images of CM CL20 (Figure 2(a)), microscale CL-20 (Figure 2(b)), and nanoCL-20 (Figures 2(c) and 2(d)) were studied together with their particles sizes and average particle sizes which were measured from the FE-SEM images. The results indicate that the samples of CL-20 prepared via ball milling and USEA methods still retain the structural integrity. However, the morphology of particles prepared by USEA method is sphere-like which are of greatly different appearance from the original particles' spindle shape. In particular, the samples obtained by ball milling have a certain degree of agglomeration and are inhomogeneous and they show a broad distribution of particle size within $0.5-1 \mu \mathrm{m}$, while it is obviously observed that the particles sizes of nano-CL-20 prepared are reduced and the corresponding size distribution becomes narrow as shown in Figure 2, whose average particle is about $270 \mathrm{~nm}$.

No obvious nano-CL-20 particles aggregation, specially, was observed from the SEM images. The possible reasons can be explained in which the chaotic and complex aerosol size distribution generated by the piezoelectric transducer at the aerosol production process makes the aerosol size's difference and its distribution. Thus, small aerosol size droplets crystallize small particles, and big aerosol size droplets crystallize large particles in the crystallization step. What is more, the repulsive force existing in the electrostatic field among nanoparticles inhibits the agglomeration of crystals with each other. Additionally, ultrasound effect can also diminish the size to nanoscale.

3.2. Structural Characterization. Bulk CL-20 has four stable forms under ambient conditions, namely, $\alpha, \beta, \gamma$, and $\varepsilon[18$, 19]. The crystal structures of CM CL-20 (a), micro-CL-20 (b), and nano-CL-20 (c) were investigated by powder XRD patterns, as shown in Figure 3. The patterns show that the microand CM materials as used exhibit a high crystallization and exhibit almost the same XRD patterns. The diffraction peaks at $2 \theta$ values of $12.6^{\circ}, 13.8^{\circ}$, and $30.3^{\circ}$ were assigned to the $\varepsilon$ CL-20 phase which are consistent with the Huaxiong et al. [20] and Lee et al.s [21] reports. The nano-CL-20 samples exhibit different XRD patterns, and it was found that the patterns exhibit a strong diffraction peak at $13.6^{\circ}, 28.2^{\circ}$, and $24.1^{\circ}$, which corresponded to the (111), (212), and (132) crystal faces $2 \theta$ of $\beta$ phase form (JCPDS 52-2432), demonstrating that the obtained crystal structure of nano-CL-20 was $\beta$ phase [22]. This process obeys Ostwald's ruler [23] of stages. Ostwald stated that an unstable system could transform into another transient state, the formation of which is attained by the smallest loss of free energy before finally reaching a stable state. It is generally known that crystallization process is mainly affected by the dynamic. Although the $\varepsilon$ form of CL20 was thermodynamically stable, yet the metastable $\beta$ form can be generated by controlling dynamic factors. Meanwhile, Kalyon et al. $[24,25]$ demonstrated that the purity of products influenced the polymorph type of CL-20, and the impurity of products can generate the formation of $\beta$ CL-20. Therefore, 


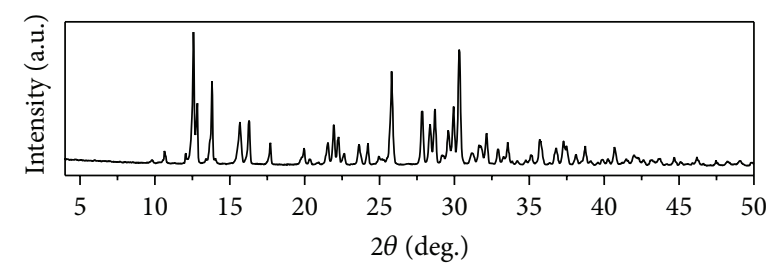

(a) CM CL-20

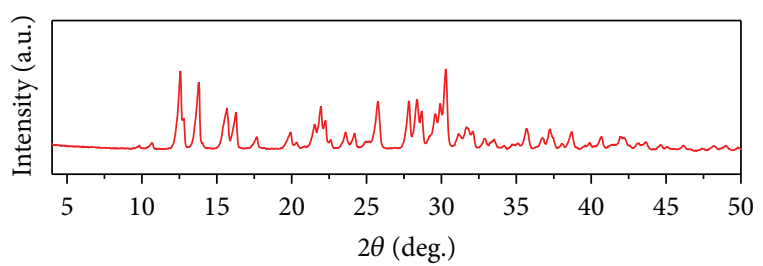

(b) Micro-CL-20

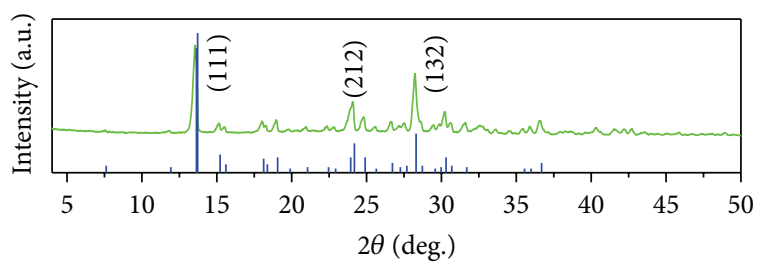

(c) Nano-CL-20

FIGURE 3: XRD diffraction patterns of the CM CL-20 (a), microCL-20 (b), and nano-CL-20 (c). The blue bars are plotted diffraction patterns of $\beta$ CL-20 (JCPDS 52-2432) (c).

the formation of $\beta$ CL-20 may be attributed to the impurity of CL-20 CM materials. Therefore, the $\beta$ phase of nano-CL20 crystals was obtained with a high evaporation rate and the temperature.

The FT-IR spectroscopy was carried out to further characterize the nano-CL-20 structure. FT-IR spectra of raw carried out of raw CL-20 (SI Figure 2(a)), micro-CL-20 (SI Figure 2(b)), and nano-CL-20 (SI Figure 2(c)) showed the characteristic band of $\mathrm{C}-\mathrm{H}$ and $-\mathrm{NO}_{2}$ functional group wave number ranges in the $3000-3100 \mathrm{~cm}^{-1}$ and $1332-1620 \mathrm{~cm}^{-1}$, respectively. The nano-CL-20 is different from that of raw CL20 and micro-CL-20. The double bands in the region 3000$3100 \mathrm{~cm}^{-1}$ are due to the absorption of six cage $(\mathrm{C}-\mathrm{H})$ bonds. The bands at 1558 and $1332 \mathrm{~cm}^{-1}$ can be attributed to the asymmetric and symmetric stretching of $-\mathrm{NO}_{2}$ groups. Moreover, Figure 4 shows the FT-IR scans of fingerprint region $\left(600-900 \mathrm{~cm}^{-1}\right)$. Four bands at $750 \mathrm{~cm}^{-1}$ are characteristic absorption bands of $\varepsilon$-CL-20. The $\varepsilon$-CL-20 characteristic peaks at $820.2 \mathrm{~cm}^{-1}$ and $855.4 \mathrm{~cm}^{-1}$ are bimodal distribution. However, $\beta$ form characteristic peaks at $835.4 \mathrm{~cm}^{-1}$ are single peak distribution in the region $800-850 \mathrm{~cm}^{-1}$ [26]. Thus, it can be concluded that nano-CL-20 with $\beta$ form was prepared, which is also consistent with the results of XRD patterns.

3.3. Solution Concentration. The aerosol droplet size is fixed when the ultrasonic frequency is constant. Namely, the numbers of explosives molecular in microdroplets increased
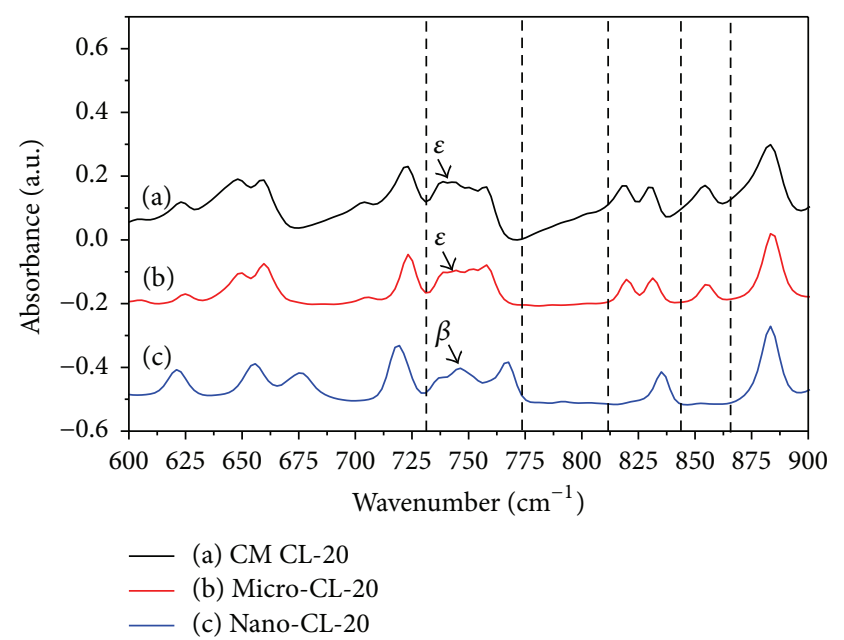

FIGURE 4: FT-IR spectra of CM CL-20 (a), micro-CL-20 (b), and nano-CL-20 (c) in the fingerprint region of $600-900 \mathrm{~cm}^{-1}$.

with the solution concentration increasing, and the crystal particles sized also become larger. Therefore, to evaluate the effect of solution concentration on the size distribution of nano-CL-20, different concentrations of CL-20 have been employed. The SEM images and corresponding distribution of CL-20 with different concentrations including $3 \mathrm{wt} \%$ (Figures 5(A) and 5(a)), $2 \mathrm{wt} \%$ (Figures 5(B) and 5(b)), $1 \mathrm{wt} \%$ (Figures 5(C) and 5(c)), and $0.5 \mathrm{wt} \%$ (Figures 5(D) and 5(d)) were shown in Figure 5. It is clearly seen that there are many aggregated particles at high concentrations. The mean size of nano-CL-20 particles is about $270 \mathrm{~nm}$ at low concentration (0.5 wt\%). Moreover, the amount of small CL-20 particles increased at lower concentration. A major reason is that the mass of droplets and the opportunity of particles decrease in the evaporation process.

Meanwhile, the trend curve (SI Figure 3) shows the trends of particle size at different concentrations (3 wt\%, $2 \mathrm{wt} \%, 1 \mathrm{wt} \%$, and $0.5 \mathrm{wt} \%$, inert gas flow $60 \mathrm{~mL} \cdot$ minute $^{-1}$ ). It indicates that mean particle size gradually decreased along with concentration reducing. When it is below $1 \mathrm{wt} \%$, it decreased at a relatively slow rate, probably because the diameters were controlled mainly by other conditions, such as gas flows and evaporated temperature.

3.4. Thermal Analysis and Thermal Stability Properties. The thermal properties of the CM CL-20, micro-CL-20, and prepared CL-20 were investigated using DSC and TG measurements. Figure 6 shows DSC curves of the conventionally manufactured CL-20 (Figure 6(a)), micro-CL20 (Figure 6(b)), and nano-CL-20 (Figure 6(c)). From the DSC curve, the thermal behaviour of CL-20 includes an endothermic process with solid-solid phase transition. The endothermic response indicates that a phase transition is occurring in CL-20 molecule. As shown in Figure 6, three endothermic peaks are observed at $171^{\circ} \mathrm{C}, 156^{\circ} \mathrm{C}$, and $151^{\circ} \mathrm{C}$, which are ascribed to the $\varepsilon \rightarrow \gamma$ phase translation temperature of CM CL-20, micro-CL-20, and CL-20, respectively. 


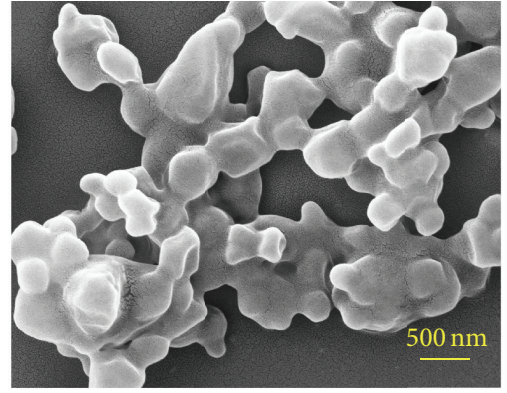

(A)

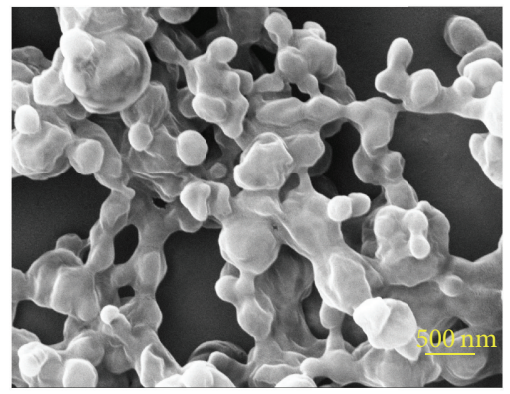

(B)

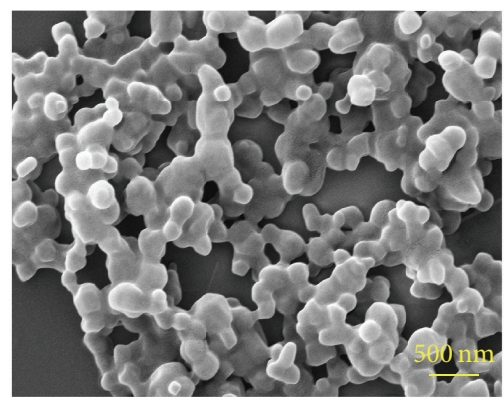

(C)

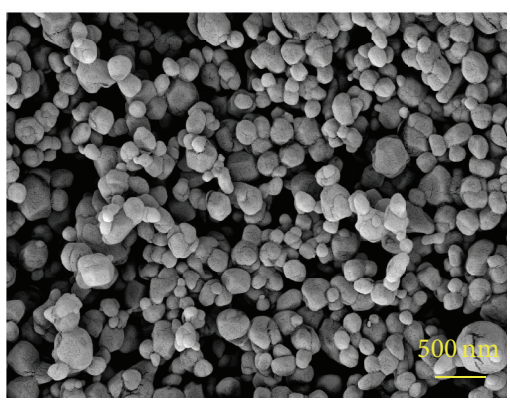

(D)

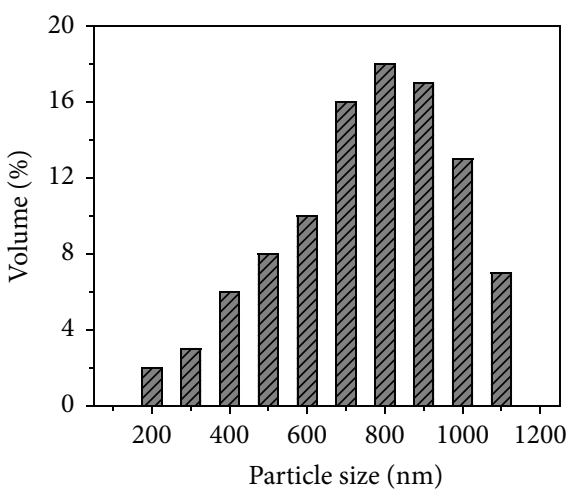

(a)

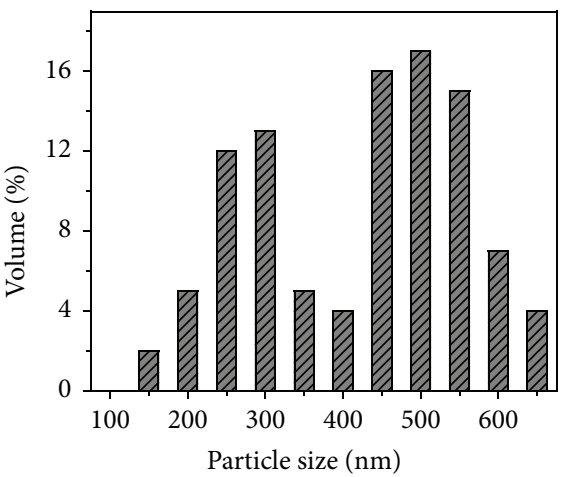

(b)

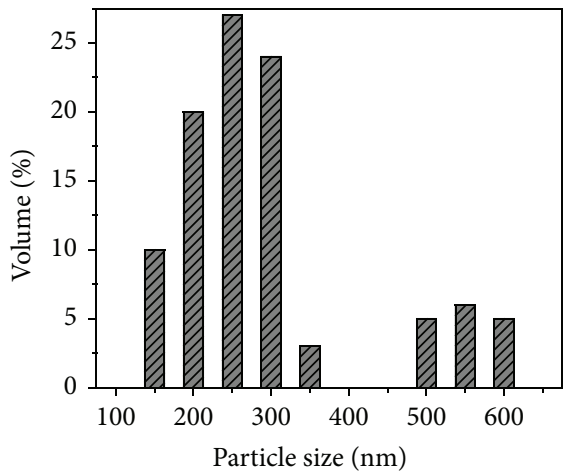

(c)

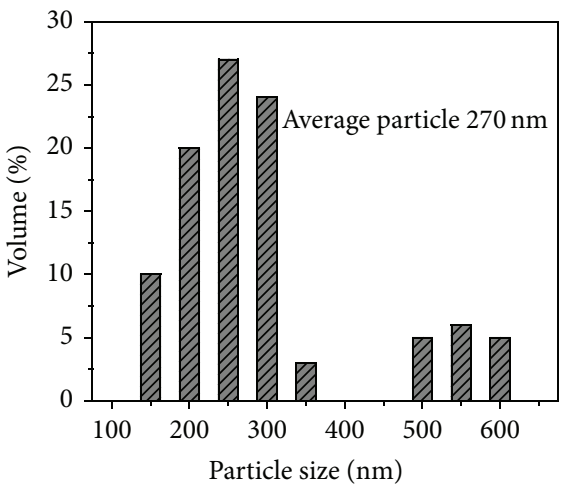

(d)

FigURE 5: SEM images and particle distribution of CL-20 prepared from (a) $3 \mathrm{wt} \%$, (b) $2 \mathrm{wt} \%$, (c) $1 \mathrm{wt} \%$, and (d) $0.5 \mathrm{wt} \%$ at the inert gas flow $60 \mathrm{~mL} \cdot \mathrm{minute}^{-1}$. 
TABLE 1: Thermal properties of the raw, superfine, and nano-CL-20 crystals.

\begin{tabular}{lccc}
\hline CL-20 & Average particle $(\mu \mathrm{m})$ & Phase transition temperature $\left({ }^{\circ} \mathrm{C}\right)$ & The maximum decomposition temperature $\left({ }^{\circ} \mathrm{C}\right)$ \\
\hline Raw & 40 & 171.0 & 244.7 \\
Micro & 0.5 & 156.0 & 235.5 \\
Nano & 0.26 & 151.4 & 232.9 \\
\hline
\end{tabular}

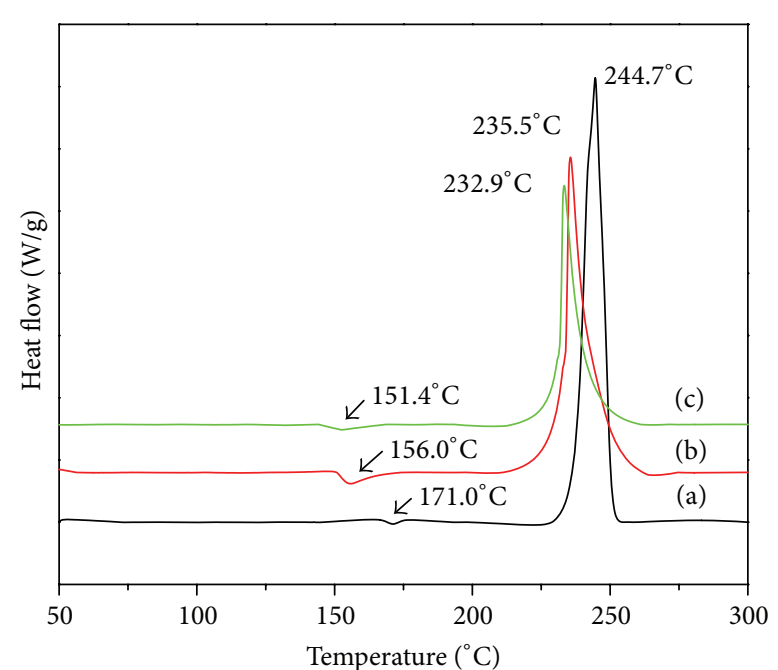

Figure 6: DSC curve of the CM CL-20 (a), micro-CL-20 (b) prepared by ball milling, and nano-CL-20 (c).

The crystal phase transition is attributed to the transformation of $\mathrm{N}^{-\mathrm{NO}_{2}}$ groups of CL-20. It should be noted that the phase translation temperature of nano-CL-20 is lower than that of CM and micro-CL-20. The reason can be explained as follows. It is considered that the difference is caused by the particle size distributions of nano-CL-20 and micro-CL-20. Small nano-CL-20 crystals have better reaction activity, leading to low phase translation temperature.

Exothermal reactions have been one of the most important properties of explosives. The DSC data of nano-CL-20 (Figure 6(c)), shows an exothermic decomposition process at the temperature range of $220-250^{\circ} \mathrm{C}\left(T_{\max }=232.9^{\circ} \mathrm{C}\right)$ at heating rate of $10^{\circ} \mathrm{C} / \mathrm{min}$. However, for the $\mathrm{CM}$ materials and micro-CL-20, $T_{\max }$ of exothermic decomposition is $244.7^{\circ} \mathrm{C}$ and $235.5^{\circ} \mathrm{C}$, respectively. The value is higher than that of nano-CL-20; namely, there is a shift of $12^{\circ} \mathrm{C}$ and $3^{\circ} \mathrm{C}$ to lower temperature. The result shows that the second peak of CL-20 typically decreased with a decrease in size which is similar to the former works of others [1]. This probably reasons why the ratio of surface atoms to interior atoms is higher than that of CM and micro-CL-20 which leads to a higher surface energy and the decrease of decomposition peak. The comparison of raw, micro-, and nano-CL-20 in thermal behaviour was shown in Table 1.

Figure 7 gives the TG curves of the raw, micro-CL-20, and prepared nano-CL-20. The TG curves of the CM and micro-CL-20 showed three obvious decomposition steps, while nano-CL-20 only showed two vertical steps which was in accordance with the DSC results. TG curve together

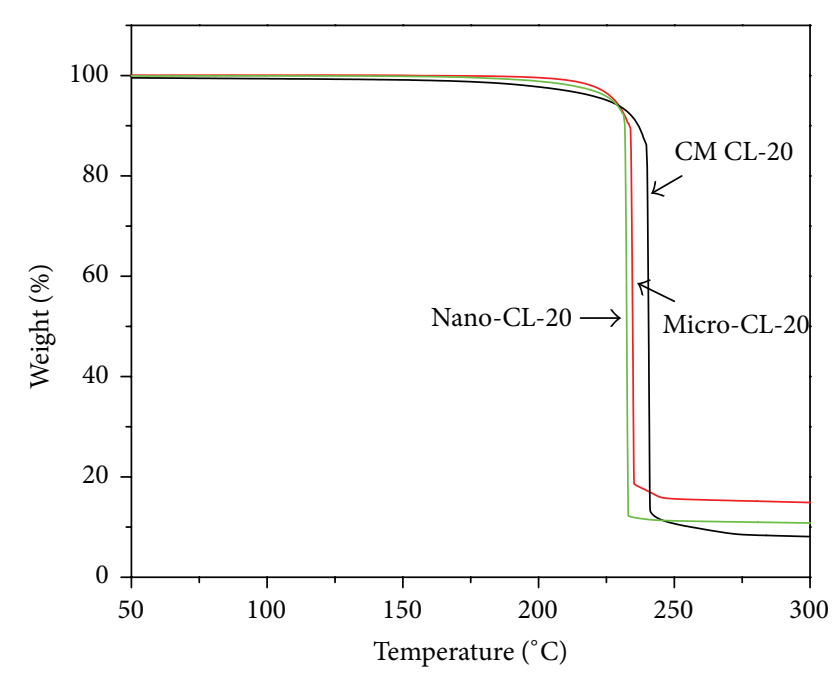

Figure 7: TG curve of the CM CL-20 (a), micro-CL-20 (b), and nano-CL-20 (c).

with the DSC curve shows that nano-CL-20 has a higher decomposition rate than that of CM and micro-CL-20.

\section{Conclusions}

In conclusion, nano-CL-20 explosive materials were successfully prepared by using USEA method. The average particle size of nano-CL-20 is about $270 \mathrm{~nm}$. A different characterization shows that nano-CL-20 particles prepared by USEA method have faster energy release efficiency and more energy release than the conventionally manufactured CL-20 and micro-CL-20, because of their less lattice defects and smaller internal stress, which was from the decrease of the particle size. The nanosized crystals can be continuously and safely produced via USEA method which may provide an effective method for industrial production. This method can be easily extended for the preparation of other energetic nanomaterials and organic nanoparticles.

\section{Conflict of Interests}

The authors declare that there is no conflict of interests regarding the publication of this paper.

\section{Acknowledgments}

This work was supported by the Scientific Research Fund of Sichuan Provincial Education Department (Project 13zd1114). 


\section{References}

[1] A. T. Nielsen, S. L. Christian, D. W. Moore, R. D. Gilardi, and C. F. George, "Synthesis of 3,5,12-triazawurtzitanes (3,5,12triazatetracyclo[5.3.1.12,604,9]dodecanes)," Journal of Organic Chemistry, vol. 52, no. 9, pp. 1656-1662, 1987.

[2] O. Bolton and A. J. Matzger, "Improved stability and smartmaterial functionality realized in an energetic cocrystal," Angewandte Chemie - International Edition, vol. 50, no. 38, pp. 91229125, 2011.

[3] J. H. Urbelis, V. G. Young, and J. A. Swift, "Using solvent effects to guide the design of a CL-20 cocrystal," CrystEngComm, vol. 17, no. 7, pp. 1564-1568, 2015.

[4] J. H. Urbelis and J. A. Swift, "Solvent effects on the growth morphology and phase purity of CL-20," Crystal Growth \& Design, vol. 14, no. 4, pp. 1642-1649, 2014.

[5] A. K. Mandal, U. Thanigaivelan, R. K. Pandey, S. Asthana, R. B. Khomane, and B. D. Kulkarni, "Preparation of spherical particles of 1,1-diamino-2,2-dinitroethene (FOX-7) using a micellar nanoreactor," Organic Process Research \& Development, vol. 16, no. 11, pp. 1711-1716, 2012.

[6] G. C. Yang, F. D. Nie, J. L. Li, Q. Guo, and Z. Qiao, "Preparation and characterization of nano-NTO explosive," Journal of Energetic Materials, vol. 25, no. 1, pp. 35-47, 2007.

[7] R. Sivabalan, G. M. Gore, U. R. Nair, A. Saikia, S. Venugopalan, and B. R. Gandhe, "Study on ultrasound assisted precipitation of CL-20 and its effect on morphology and sensitivity," Journal of Hazardous Materials, vol. 139, no. 2, pp. 199-203, 2007.

[8] A. Elbeih, A. Husarova, and S. Zeman, "Path to $\varepsilon$-HNIW with reduced impact sensitivity," Central European Journal of Energetic Materials, vol. 8, no. 3, pp. 173-182, 2011.

[9] N. Zohari, M. H. Keshavarz, and S. A. Seyedsadjadi, "The advantages and shortcomings of using nano-sized energetic materials," Central European Journal of Energetic Materials, vol. 10, no. 1, pp. 135-147, 2013.

[10] X. Guo, G. Ouyang, J. Liu et al., "Massive preparation of reduced-sensitivity nano CL-20 and its Characterization," Journal of Energetic Materials, vol. 33, no. 1, pp. 24-33, 2014

[11] J. Wang, J. Li, C. An, C. Hou, W. Xu, and X. Li, "Study on ultrasound- and spray-assisted precipitation of CL-20," Propellants, Explosives, Pyrotechnics, vol. 37, no. 6, pp. 670-675, 2012.

[12] V. Stepanov, L. N. Krasnoperov, I. B. Elkina, and X. Zhang, "Production of nanocrystalline RDX by rapid expansion of supercritical solutions," Propellants, Explosives, Pyrotechnics, vol. 30, no. 3, pp. 178-183, 2005.

[13] W. H. Suh and K. S. Suslick, "Magnetic and porous nanospheres from ultrasonic spray pyrolysis," Journal of the American Chemical Society, vol. 127, no. 34, pp. 12007-12010, 2005.

[14] J. H. Bang and K. S. Suslick, "Applications of ultrasound to the synthesis of nanostructured materials," Advanced Materials, vol. 22, no. 10, pp. 1039-1059, 2010.

[15] J.-W. Kim, M.-S. Shin, J.-K. Kim, H.-S. Kim, and K.-K. Koo, "Evaporation crystallization of RDX by ultrasonic spray," Industrial \& Engineering Chemistry Research, vol. 50, no. 21, pp. 12186-12193, 2011.

[16] D. Spitzer, C. Baras, M. R. Schäfer, F. Ciszek, and B. Siegert, "Continuous crystallization of submicrometer energetic compounds," Propellants, Explosives, Pyrotechnics, vol. 36, no. 1, pp. 65-74, 2011.
[17] B. Risse, D. Spitzer, D. Hassler et al., "Continuous formation of submicron energetic particles by the flash-evaporation technique," Chemical Engineering Journal, vol. 203, pp. 158-165, 2012.

[18] Y. T. Lapina, A. S. Savitskii, E. V. Motina, N. V. Bychin, A. A. Lobanova, and N. I. Golovina, "Polymorphic transformations of hexanitrohexaazaisowurtzitane," Russian Journal of Applied Chemistry, vol. 82, no. 10, pp. 1821-1828, 2009.

[19] V. D. Ghule, P. M. Jadhav, R. S. Patil, S. Radhakrishnan, and T. Soman, "Quantum-chemical studies on hexaazaisowurtzitanes," The Journal of Physical Chemistry A, vol. 114, no. 1, pp. 498-503, 2010.

[20] C. Huaxiong, C. Shusen, L. Lijie, and J. Shaohua, "Quantitative determination of $\varepsilon$-phase in polymorphic HNIW using X-ray diffraction patterns," Propellants, Explosives, Pyrotechnics, vol. 33, no. 6, pp. 467-471, 2008.

[21] M.-H. Lee, J.-H. Kim, Y.-C. Park, J.-H. Hwang, and W.-S. Kim, "Control of crystal density of $\mathcal{\varepsilon}$-hexanitrohexaazaisowurzitane in evaporation crystallization," Industrial and Engineering Chemistry Research, vol. 46, no. 5, pp. 1500-1504, 2007.

[22] X.-B. Jiang, X.-Y. Guo, H. Ren, Y.-L. Zhu, and Q.-J. Jiao, “Control of particle size and shape of $\varepsilon$-HNIW in Drowning-out crystallization," Journal of Chemical Engineering of Japan, vol. 45, no. 6, pp. 380-386, 2012.

[23] J. Nývlt, "The ostwald rule of stages," Crystal Research and Technology, vol. 30, no. 4, pp. 443-449, 1995.

[24] Z. Peralta-Inga, N. Degirmenbasi, U. Olgun, H. Gocmez, and D. M. Kalyon, "Recrystallization of CL-20 and HNFX from solution for rigorous control of the polymorph type: part I, mathematical modeling using molecular dynamics method," Journal of Energetic Materials, vol. 24, no. 2, pp. 69-101, 2006.

[25] R. Yazici and D. Kalyon, "Microstrain and defect analysis of CL-20 crystals by novel X-ray methods," Journal of Energetic Materials, vol. 23, no. 1, pp. 43-58, 2005.

[26] E. von Holtz, D. Ornellas, M. F. Foltz, and J. E. Clarkson, "The solubility of $\varepsilon$-CL-20 in selected materials," Propellants, Explosives, Pyrotechnics, vol. 19, no. 4, pp. 206-212, 1994. 

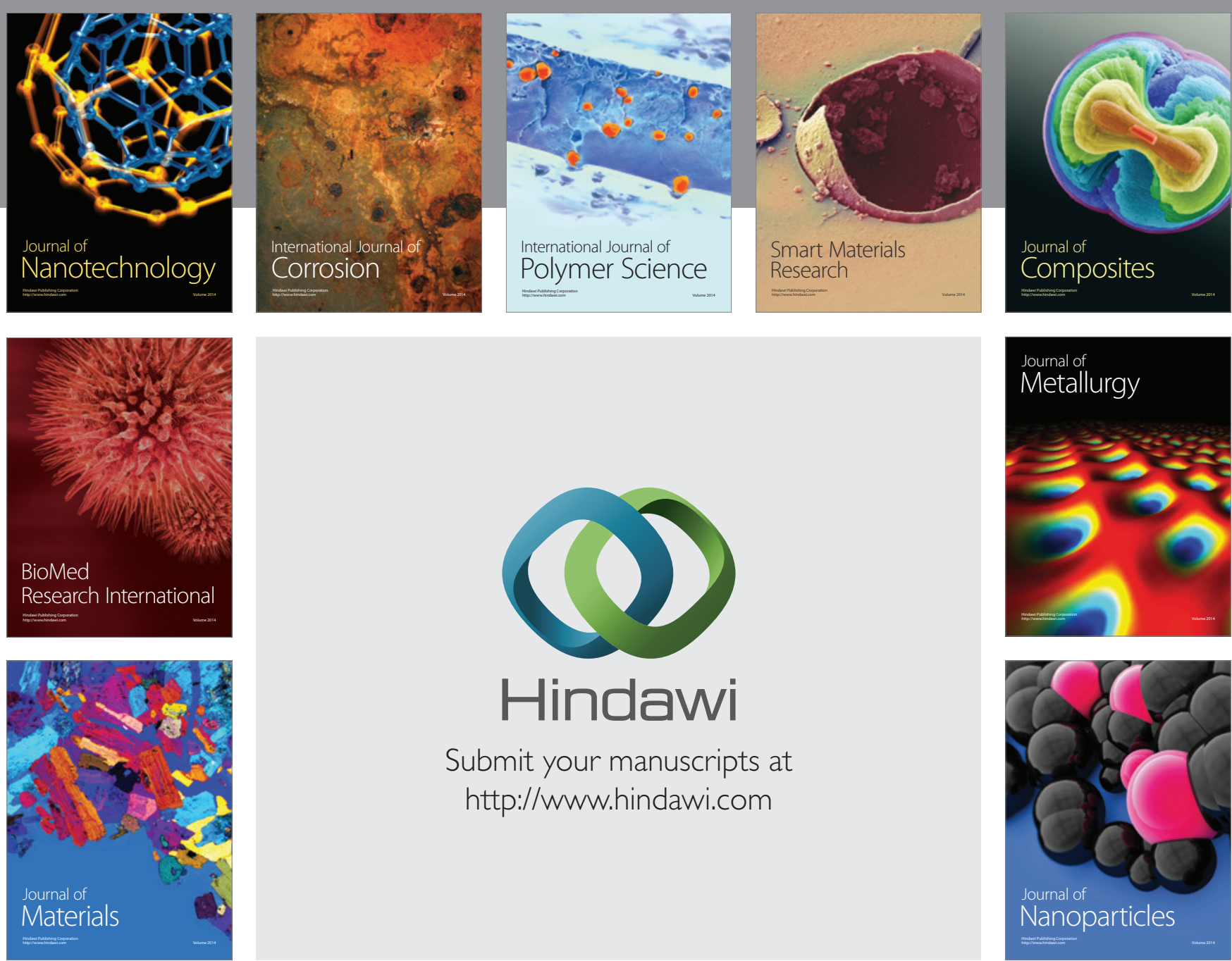

\section{Hindawi}

Submit your manuscripts at

http://www.hindawi.com

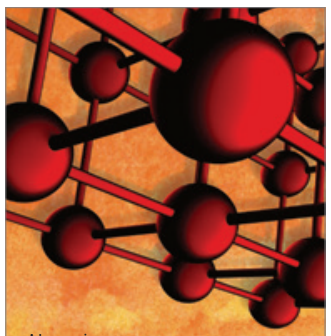

Materials Science and Engineering
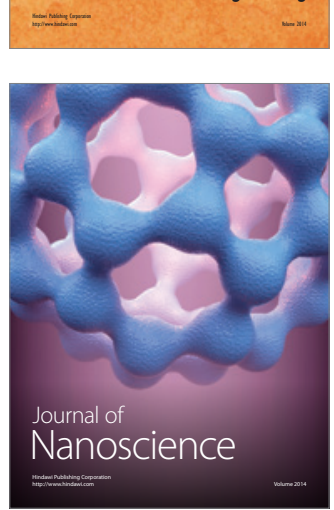
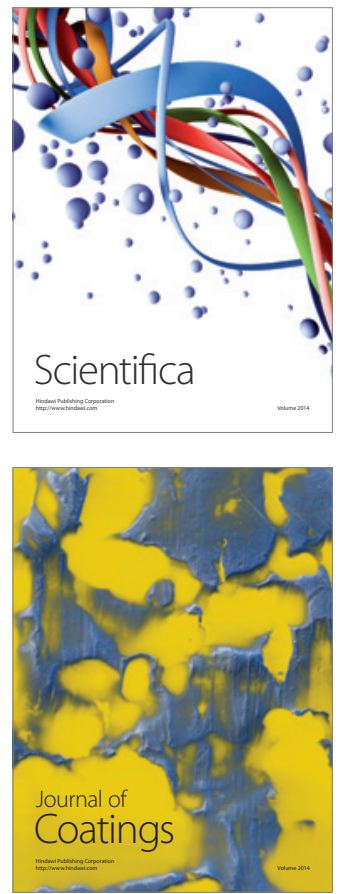
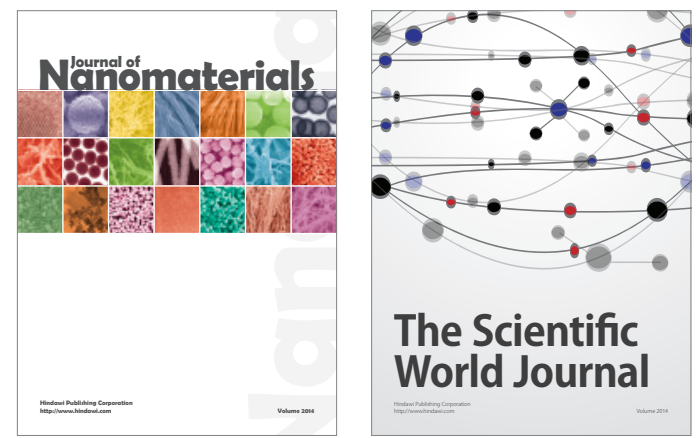

The Scientific World Journal
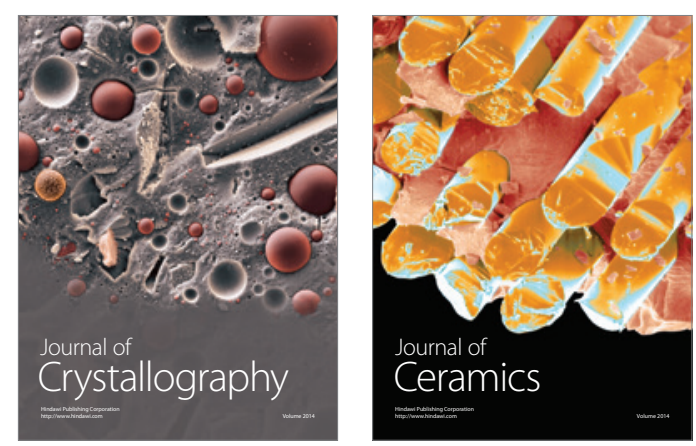
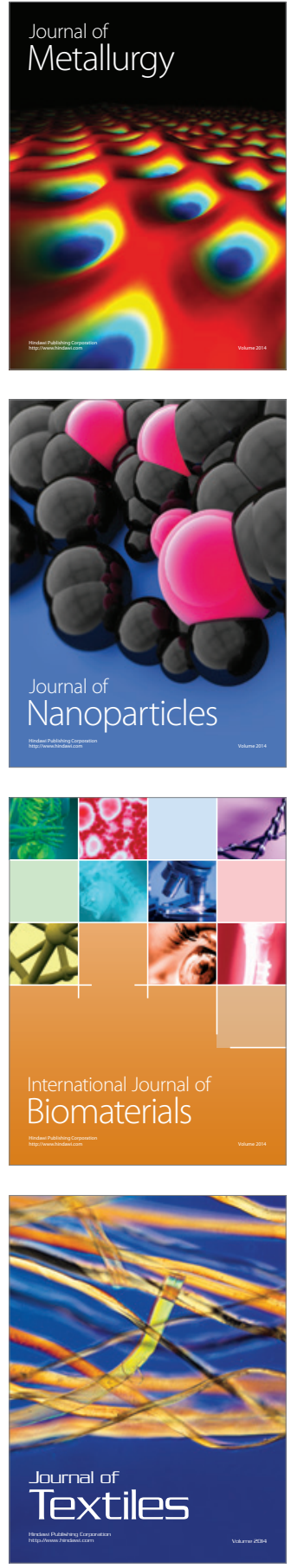